\title{
http://dx.doi.org/10.12795/RAA.2012.i02.04
}

\section{EL PATRIMONIO EN TIEMPOS DE CRISIS}

\author{
LLORENÇ PRATS \\ Universidad de Barcelona ${ }^{1}$
}

\section{Resumen}

¿Cuál es el lugar y la función del patrimonio en una situación de crisis generalizada como la presente? En este artículo se constata el auge de los procesos de patrimonialización desde las últimas décadas del siglo XX, sus causas y los problemas que plantean especialmente en tiempos de crisis como los actuales. A continuación se aborda la crisis como un contexto de oportunidades para corregir estos problemas y se plantean las líneas de desarrollo o transformación que deberían seguir las activaciones patrimoniales para servir realmente a la cohesión social y al bienestar comunitario: Para una mayor claridad, la situación se ilustra mediante el ejemplo del tratamiento del patrimonio y su relación con la población y con el turismo en un territorio de la Cataluña Interior.

Palabras clave: Patrimonio, crisis, protagonismo, turismo, cohesión social, bienestar

1. Este artículo se inscribe en el marco del Grup de Recerca Consolidat d'Anàlisi Territorial i Desenvolupament Regional (ANTERRIT), Generalitat de Catalunya, y es reflejo de los trabajos de investigación del proyecto CSO2011-27230, Nuevos turismos y desarrollo territorial en un contexto de cambio. Experiencias y oportunidades de los espacios turísticos de interior en España, financiado por el Ministerio de Ciencia e Innovación. 


\begin{abstract}
What is the place and role of heritage in a generalized crisis situation such as this? This article notes the rise of patrimonial processes since the last decades of the twentieth century, its causes and the problems especially in times of crisis like the present. Then address the crisis as a context of opportunities to correct these problems and raise the lines of development or transformation that heritage assets should follow to truly serve the social cohesion and community well-being: For clarity, the situation illustrated by the example of the treatment of heritage and its relation to population and tourism in an area of inland Catalonia.
\end{abstract}

Keywords: Heritage, crisis, protagonism, tourism, social cohesion, welfare

\title{
1. LA ECLOSIÓN PATRIMONIAL
}

En estos últimos años se ha venido produciendo una eclosión patrimonial que ha dado lugar a todo tipo de activaciones según causalidades diversas y con objetivos y efectos igualmente diversos.

De hecho es un fenómeno que se viene dando desde el inicio de la llamada "nueva museología", que podemos fechar convencionalmente en la conferencia de la UNESCO en Santiago de Chile, 1972, aunque de hecho representa una renovación continuada de las funciones y formas de presentación no sólo de los museos sino del patrimonio en general que se remonta por lo menos a la obra de Rivière (Rivière, 1993). Véase también Iniesta (1994) o Mairesse (2002) entre otros. El nacimiento y la diversificación de este fenómeno no han sido cronológicos ni territorialmente homogéneos. Crisis económicas recurrentes, confrontaciones bélicas de larga duración, pobreza endémica... han afectado con mayor o menor fuerza y persistencia a unas u otras regiones del mundo. El soberbio patrimonio de Irak, por poner un ejemplo, ha sido expoliado o devastado.

Sin embargo, a la vez ha habido muchos otros factores que, en contextos de estabilidad y bonanza, han favorecido el auge de los procesos de patrimonialización (Véanse algunos de sus más destacados ejemplos en Alcalde, Boya, Roigé, 2010; y Roigé, Frigolé, 2010).

Entre esos factores destaca el estímulo que ha supuesto la declaración de Patrimonio de la Humanidad (Convención de 1972) y Patrimonio Inmaterial de la Humanidad (Convención de 2003) por parte de la UNESCO (2008).

Por otra parte, la evolución cuantitativa y cualitativa del turismo, exigiendo cada vez más una mayor diversificación de recursos y autenticidad, como destacan Cohen (2005) Antón y González-Reverté (2007), López-Palomeque (2009) y tantos otros autores. Se trata de un estímulo complejo, no siempre bien recibido desde el sector patrimonial, pero, por otra parte, inevitable. Además, sí ha sido bien acogido, en general, por comunidades 
indígenas, que han visto en él una oportunidad para el desarrollo. Véase, por ejemplo, Pastor y Gómez (2010). Jordi Gascón (2009) ha llevado a cabo un buen análisis de los clarobscuros del llamado turismo responsable en estos ámbitos. En estos casos se da claramente una confluencia entre la vindicación identitaria y el turismo, siendo difícil determinar de forma generalizable si el turismo se convierte en motor de los procesos de etnogénesis o reetnificación, o si, en cambio, es una consecuencia derivada de estos mismos procesos, como se puede observar en estudios recientes al respecto y con matices diferenciales (Bustos, 2011; Pereiro, 2011; Mancinelli, 2011). Esto se vincula asimismo con los procesos de globalización que han dado lugar a reacciones locales en lo que algunos autores, como Robertson (1992) y más tarde Beck (2004) y otros han llamado glocalización y a la que, en otros lugares, han contribuido también las migraciones y la diversidad cultural. Migraciones, estabilización de la población inmigrante y turismo son tres fenómenos diversos entre sí y en su relación con la cultura anfitriona, pero que comparten su capacidad diferencial de interpelarla y poner en marcha mecanismos de integración, exclusión y representación en todos los cuales participa el patrimonio.

Esta misma demanda turística ha ejercido su efecto sobre las ciudades y los centros históricos ${ }^{2}$. Se trata de un fenómeno complejo, con frecuencia unificado bajo el concepto de gentrificación, que, por una parte, no es atribuible únicamente al turismo sino al propio desarrollo de las burguesías urbanas (Cócola, 2011) y, por otra, se ha visto sujeto a una estigmatización genérica que ha obstruido en muchas ocasiones la investigación objetiva y serena. En todo caso, en lo que respecta al patrimonio, debería distinguirse en ese sentido entre la atracción de los iconos como tales (los lugares) y la de los objetos patrimoniales a veces albergados en los mismos y que en cualquier caso es distinta (como puede observarse en las cifras de visitantes a los monumentos y a los museos).

Otro movimiento, si no general por lo menos desigualmente presente en todo el mundo mínimamente desarrollado, es la reivindicación de la memoria pretendidamente colectiva, aunque sería más apropiado hablar de discursos construidos a partir de recuerdos (no sólo) y compartidos por grupos afines y fijados jerárquicamente, distintos y más o menos divergentes entre ellos, pero en cualquier caso limitados (Prats, 2005). Esto se ha producido especialmente en aquellos países que han sufrido en un pasado más o menos reciente estados de represión sangrienta, como sería el caso de Chile y otros países latinoamericanos, o el caso de España y de los memoriales democráticos de la represión franquista, que hasta hoy han constituido un tema tabú (recordemos la persecución legal que aún sigue sufriendo en este sentido el juez Baltasar Garzón).

2. Sobre los centros históricos de todo el mundo y sus procesos de reconversión hay una extensísima bibliografía y un debate muy vivo. Por poner un solo ejemplo, véase para Latinoamérica, la revista Centro- $h$, publicada por la Organización Latinoamericana y del Caribe de Centros Históricos. En nuestro país es especialmente prolijo el debate sobre el supuesto modelo Barcelona, que ha implicado a diversos autores de distintas disciplinas. 
Debe notarse la paradoja que se produce en este ámbito entre la patrimonialización (y por ende fijación) de los lugares (los escenarios de la Batalla del Ebro, por ejemplo) y la recuperación de una memoria histórica capaz aún de remover sentimientos y conflictos.

Otros fenómenos afectan más específicamente a los procesos de patrimonialización en zonas distintas entre sí. Por ejemplo la necesidad de recrear identidades nacionales en los países reindependizados del bloque soviético, o en las comunidades autónomas del Estado Español después de la constitución de 1978 y que sigue hasta el presente, combinándose con la necesidad de diferenciarse en áreas más coherentes a efectos especialmente turísticos y tal vez identitarios.

El llamado patrimonio industrial también ha constituido una vía de expansión de las activaciones patrimoniales, especialmente en antiguas zonas fabriles que se han visto afectadas por procesos de reconversión y de deslocalización, pero también, muy vinculado al turismo denominado "de experiencia", la llamada "industria viva", con ejemplos tan vigorosos como el del enoturismo, con visitas a bodegas, paisajes vitivinícolas y museos del vino (Elías, 2006).

Finalmente, muchas disciplinas académicas han buscado salidas sociales y profesionales en el patrimonio (literario, etc.), casi siempre con los ojos puestos en el turismo, mientras que otras actividades económicas han buscado un valor añadido para la atracción de consumidores, como en el caso de la gastronomía y los "productos de la tierra", las dietas localizadas (la cocina volcánica...). No olvidemos que determinados sistemas gastronómicos (como la dieta mediterránea o la gastronomía mexicana o la francesa) han sido designados patrimonio inmaterial de la humanidad.

A todo eso cabe añadir la proliferación de figuras de activación patrimonial: rutas, centros de interpretación, centros de acogida... y una evidente independización de la museología y la museografía, de la expología en palabras de Jacques Hainard (2008), que se ha constituido prácticamente como una disciplina autónoma, un lenguaje en sí misma, con independencia de los referentes patrimoniales.

\section{LA CRISIS}

En este estado, que podríamos llamar de hiperpatrimonialización de la realidad, se produce un alud de quiebras económicas en cascada, un verdadero efecto dominó, en los especulativos mercados financieros, especialmente vinculadas a un desmedido afán de lucro mediante la especulación inmobiliaria más allá de cualquier límite de riesgo razonable (Ramonet, 2011). Las fortunas y grandes fondos de inversión y con ellos la banca sufren importantes pérdidas cuando se desmorona la pirámide y exigen a los estados en última instancia que las cubran. Con la excusa de que estaban jugando con el dinero de todos y que abandonarlos a su suerte sería catastrófico, los estados, en lugar de limitarse a garantizar los depósitos de los ciudadanos poniéndolos a buen recaudo en una 
banca pública y dejando a los especuladores a su suerte, comprometen el dinero de todos en restituir las amenazadas fortunas y fondos de inversión, y, puesto que esto no basta aun vaciando las arcas públicas, aplican progresivamente una serie de medidas, cada vez más asfixiantes, sobre las clases populares y medias y el estado del bienestar. Ningún rico se arruina pero muchas personas humildes van al paro, pierden sus casas, a veces la esperanza y hasta sus vidas ${ }^{3}$. El estado, cada vez más debilitado, reduce drásticamente sus gastos, y las partidas dedicadas a cultura, y particularmente a patrimonio, se ven muy seriamente afectadas. Se reducen subvenciones, se paralizan proyectos, tanto a nivel local como autonómico y estatal. Y esto se advierte especialmente en los países capitalistas desarrollados, el epicentro de la crisis, particularmente en aquellos donde el estado ha desarrollado siempre un papel protagonista en estos ámbitos. Indirectamente, puede afectar a otros países, por la disminución del gasto turístico de segmentos de público procedente de los países afectados, pero en los países más golpeados por la llamada crisis, como Grecia, Portugal, Italia, España o Irlanda, la inversión patrimonial se reduce, de momento, a límites que apenas garantizan el mantenimiento de las activaciones existentes. Y la situación apunta hacia un empeoramiento y, si no a una cronificación, si por lo menos a una situación de larga duración.

En esta coyuntura, independientemente de otras discusiones sobre cómo superar la situación a que nos han abocado (que sin duda deben tenerse), cuando se están produciendo recortes muy graves en sanidad y educación (además de otras partidas también muy sensibles) nadie puede pretender que se priorice o siquiera se mantenga la inversión pública en patrimonio.

En Cataluña, el gobierno de la Generalitat ha encargado a una empresa de servicios culturales la elaboración de un Plan Estratégico de la Cultura 2011-2021. Este plan, a partir de unos principios metodológicos generales, está siendo presentado y debatido con especialistas a partir de dos ejes, uno temático y otro territorial. El eje temático adopta la clasificación de la UNESCO para las estadísticas culturales (2009): Patrimonio natural y cultural; Interpretación y celebración; Artes visuales y artesanía; Libros y prensa; Medios audiovisuales y Media interactivos; y Diseño y servicios creativos. Como sectores relacionados contempla el turismo, por una parte, y el deporte y la recreación, por otra. Para el eje territorial, se han tomado como unidad de estudio y debate las vegueries (siete en total en Cataluña) que son una demarcación intermedia entra las provincias (a las que aspiran a sustituir) y las comarcas, contempladas en una futura Ley de Veguerías pero sin entidad legal ni funcionalidad política por el momento. El preestablecimiento de la metodología por parte de le empresa redactora, la doble fragmentación temática y territorial y la designación de los consultores por parte del gobierno hacen que, en el

3. Según Andy Robinson (2011), Grecia ha registrado un aumento de suicidios del 40\% en lo que va de año. 
fondo, lo que se quiere presentar como un proceso participativo no sea más que una consulta formal de la que el Departamento de Cultura puede tomar las sugerencias que le convengan. Pero hay más. En todos los sectores y específicamente en el de patrimonio natural y cultural, que es el que nos atañe, la cultura (el patrimonio en este caso) se presenta como un elemento de cohesión social y bienestar, por una parte, y de desarrollo económico, por otra.Tal como se presentaron en el ámbito temático de patrimonio, estas características intrínsecas de la cultura constituirían una evidencia que nosotros (los expertos) conocemos perfectamente y el plan debería contemplar como hacer entender esta obviedad a la sociedad, para que los gastos e inversiones en patrimonio no fueran vistos como absolutamente prescindibles. Pero esto no es así, no es necesariamente cierto que el patrimonio genere cohesión social y bienestar ni mucho menos desarrollo económico. Lo cierto es que el patrimonio se ha planificado y gestionado de arriba abajo con muy escasa y elitista participación social. La sociedad nunca ha sido la protagonista de la planificación y gestión del patrimonio y, por tanto, difícilmente se le puede atribuir ninguna capacidad de cohesión social —es más, en muchos casos ha sido excluyente(Prats, 2008) y el bienestar social que ha procurado se limita al placer de la contemplación que hayan podido obtener supuestamente los visitantes. Cuando se habla de cohesión social se está pensando, en este contexto, en cohesión identitaria, o incluso mejor, en cohesión nacional (catalana en este caso) de acuerdo con la definición de "lo catalán" que haga el partido en el gobierno (la derecha nacionalista actualmente) y que ahora, por cierto, en palabras de su vicepresidenta, contempla como rasgo característico del "carácter catalán", además de los habituales, la "austeridad". Tampoco es ni mucho menos cierto que el patrimonio genere desarrollo económico, ni tan siquiera que tenga en muchos casos una sostenibilidad en sí mismo. A esto me he referido en diversas ocasiones (Prats, 2003; 2011).

Creo que estas afirmaciones de verticalidad en el tratamiento del patrimonio, ausencia de protagonismo social y limitado o nulo efecto económico en muchos casos se pueden extender a gran cantidad de situaciones y contextos, en cualquier caso las remito y reafirmo en el caso de Cataluña, que conozco bien y sobre el cual, después veremos un ejemplo.

A pesar de todo, existe un cierto autismo en el mundo de la gestión patrimonial, que le lleva a continuar hablando de sus asuntos como si no pasara nada. Sin embargo sí pasa, y mucho, porque, aun suponiendo que se llegara a establecer un reequilibrio social (vía reforma impositiva, por ejemplo), que permitiera volver a crear riqueza y recuperar mínimamente los estándares anteriores, si una virtud tiene esta crisis, es que está dejando al descubierto los abusos y disfunciones estructurales de la administración y la irracionalidad y descontrol de muchos gastos, y éste es (o debería ser) un camino sin vuelta atrás. 


\section{EL PATRIMONIO EN TIEMPOS DE CRISIS}

Por tanto, en cierta manera, puede considerarse la crisis como una oportunidad para repensar el sector patrimonial en España y en otros países. Y remarco lo de "en cierta manera" porque hablar de oportunidades en estos momentos no deja de tener un punto sarcástico.

Esta oportunidad debería convertirse en un proceso de racionalización de la oferta en sus diversas vertientes y sus usos al servicio del bienestar social.

El punto de partida debe ser que, en un momento de recorte de prestaciones básicas, independientemente de lo razonables o no que nos parezcan esos recortes, la conservación y difusión del patrimonio no puede ser una prioridad en sí. Tampoco se puede pretender que el patrimonio, en general, sea capaz de generar ocupación.

Sin embargo, hay tres líneas, por lo menos, en las cuales el patrimonio puede contribuir sustantivamente a mejorar el bienestar socioeconómico de la población.

La primera implica forzar su asociación con el turismo donde sea posible. La asociación entre turismo y patrimonio no siempre es posible ni deseable (Prats, 2011), pero, cuando lo es, el patrimonio puede reforzar, dar vida a un sector económico potencialmente muy importante y cuya nobleza a veces se ve empañada por malas prácticas dentro del mismo sector turístico o en relación con el patrimonio. El turismo en sí, entendido como disfrute de un tiempo de ocio fuera de la residencia habitual, representa un importante logro social de las clases medias occidentales que, de forma lenta pero imparable se ha ido extendiendo a otros segmentos sociales. No es tan importante cómo se use ese tiempo de ocio, si para disfrutar de la naturaleza o recorrer ciudades, como qué tipos de impactos y efectos ecológicos, económicos y culturales tiene el fenómeno en su conjunto en un determinado lugar. Con sus peculiaridades, pero como en cualquier otra industria, en el turismo hallamos empresas grandes y pequeñas, de producción intensiva y extensiva, de capital y beneficios multinacionales o locales, que revierten o no en el destino, con unas políticas de ocupación más o menos justas y beneficiosas para la población, con mayor o menor estímulo de otros sectores productivos locales, etc. La bondad del turismo para un territorio y para el conjunto de su población depende fundamentalmente de las características de la oferta, que determinan incluso el tipo de consumidor predominante y sus expectativas. No es pues el turista en sí mismo el causante último de los impactos negativos, sino la orientación de los productos y los objetivos de las empresas. Los turistas son personas normales, o, dicho de otra manera, todos somos turistas en uno $\mathrm{u}$ otro momento $\mathrm{y}$, habitualmente, turistas generalistas, con unos u otros intereses a lo largo de nuestra vida o dentro de un mismo viaje. Lo único que diferencia a un turista de cualquier otro ciudadano es su temporal estado de ocio y, por tanto, su disposición a disfrutar de su viaje o de su estancia a partir de muy diversos estímulos. En 
determinadas situaciones, estos estímulos se pueden asociar con el patrimonio (Prats, 2011) y, en estos casos, cuando no se produce esta asociación o no es satisfactoria, las causas son atribuibles, en la inmensa mayoría de los ocasiones, a una inadecuación de las activaciones patrimoniales a la visita turística, que puede ser perfectamente respetuosa y provechosa si se adaptan discursos para este público específico, que se diferencia de otros tipos de públicos considerados más genuinos por las instituciones patrimoniales por el simple hecho de que, en su estado de ocio, deambula con curiosidad antes que con una actitud de estudio y profundización, cosas que hacemos todos en algún determinado momento.

Otra vía mediante la cual el patrimonio puede contribuir a la dinamización de la economía local es su vinculación con la producción y la comercialización especialmente de artesanías en la línea de lo que Cyrile Symard denominó economuseos (1992) e incluso más allá mediante fórmulas imaginativas que ya se han ensayado en muchos lugares del mundo. En la medida que el shopping, o las compras, tienen, especialmente en el marco del turismo, un carácter esencialmente lúdico, esta asociación se hace perfectamente viable. Por otra parte es una asociación deseable y absolutamente coherente con la visión del patrimonio como recursos para vivir (García, 1998). Patrimonio, producción y comercialización pueden constituir una interrelación con grandes posibilidades (siempre sujetas a las dimensiones y capacidad de atracción de las activaciones patrimoniales), siempre y cuando, por supuesto, formen parte de un mismo contexto cultural y mantengan una coherencia lógica. La idea de Symard (1992) de que "el patrimonio se gane la vida" no se ha desarrollado suficientemente ni adecuadamente, con la coherencia necesaria, lo cual a su vez ha redundado con frecuencia en un escepticismo al respecto. Es importante que este impulso, como otros, nazca o germine de la misma sociedad local, porque el sector patrimonial, de forma mayoritaria, se sigue viendo a sí mismo como un fin en sí, un objetivo a ser sostenido antes que una actividad que contribuya al sustento, teniendo en cuento que ambos fines, perfectamente legítimos, no son excluyentes ni contradictorios.

La segunda línea implica una reordenación cuantitativa y territorial de las activaciones patrimoniales, lo cual conlleva en definitiva una redefinición del sector para racionalizarlo y optimizar su eficiencia. Con frecuencia sobran museos y activaciones patrimoniales de otro tipo y falta planificación en este mismo sentido. Esto se debe fundamentalmente a dos causas: un localismo miope y la incapacidad de reconversión de activaciones obsoletas. La lógica de la administración y otros agentes locales ha hecho que, allá donde fuera posible, el museo o similares (centro de interpretación, etc.) fuese contemplado como un equipamiento básico, un bien deseable por si mismo para la población, bastante independientemente de sus funciones, como un indicador de la importancia de la localidad. Esta actitud, que ya he explicado en otras ocasiones (Prats, 2005) ha tenido 
como consecuencia, cuando la administración ha sido capaz de movilizar los medios, la proliferación de activaciones patrimoniales clónicas en una misma zona, contra toda lógica de gestión patrimonial y de viabilidad social y económica. Puede objetarse que esas activaciones han cumplido una función eminentemente identitaria, pero en general no es así. Como veremos en seguida, hay formas más eficientes de utilizar el patrimonio con fines identitarios, mientras que estas activaciones (museos locales mayoritariamente), por sus elevados costes de mantenimiento y su nula viabilidad turística en la mayoría de los casos, no sólo no han podido establecer un diálogo evolutivo con la sociedad sino que han llegado a constituir verdaderos quebraderos de cabeza para el erario público y han usurpado recursos que hubieran estado mejor empleados en otras iniciativas. Muchos han desaparecido y otros se mantienen artificialmente a costa del contribuyente, a modo de tótem, sin otro interés para la sociedad local ni para los visitantes.

Otra dimensión de este mismo problema puede observarse en la proliferación de museos, en este caso específicamente museos, o, según legislaciones, museos y colecciones abiertas al público en las grandes ciudades. En Cataluña, las estadísticas oficiales, de una relativa fiabilidad, abocan un número de veintidós millones de visitantes para el conjunto de museos y colecciones del país, pero la distribución es enormemente desigual, ocho o nueve instituciones mayoritariamente ubicadas en Barcelona (la excepción sería el Teatre Museu Dalí de Figueras) congregan alrededor de un 60\% de los visitantes mientras que las casi cuatrocientas instituciones restantes se reparten, también muy desigualmente, el resto. Hay dos aspectos interesantes a destacar. Uno es que los museos y colecciones más concurridos corresponden mayoritariamente a monumentos. Estos monumentos, como la Sagrada Familia, El Camp Nou o la Pedrera de Gaudí no distinguen en el recuento de entradas entre monumento y museo, por lo cual, la supuesta entrada al museo se ve exponencialmente aumentada en número. Un parque-monumento importante, el Park Güell, también de Gaudí, no cuenta el número de visitantes, estimado actualmente en torno a unos cuatro millones, sólo las entradas a la casa-museo de Gaudí, donde residía durante las obras, muy sencilla, que alcanza la relativamente discreta cifra de 400.000 visitantes anuales. He aquí pues un importante elemento para la reflexión respecto a la mencionada distinción a efectos turísticos entre iconos y contenidos.

Muchos de los pequeños museos y colecciones con números muy bajos de visitantes (y en cualquier caso del todo insuficientes para garantizar o tan siquiera contribuir notablemente a su sostenibilidad) se hallan en la ciudad de Barcelona. Obviamente, esta acumulación de equipamientos con un público objetivo idéntico o similar en un mismo contexto urbano implica todo tipo de disfunciones: un elevadísimo coste público y una cuasi invisibilidad de estas instituciones que les impide cumplir con sus funciones más elementales y, como mucho, les permite relacionarse con una escuálida élite de connaisseurs. Se ha propuesto ya más de una vez que estos pequeños museos, muchos 
de ellos de titularidad municipal, se reunieran en un solo Instituto del Patrimonio de Barcelona, con lo cual se conseguiría, entre otras cosas, reunir las colecciones y conservarlas en mejores condiciones, optimizar el personal constituyendo un equipo profesional que trabajara conjuntamente, desafectar edificios que podrían destinarse a otros usos públicos o reducir gastos cuando estos no son de titularidad pública y llevar a cabo exposiciones temáticas e interdisciplinares de más o menos larga duración y una capacidad de atracción incomparablemente mayor. A esta iniciativa municipal podrían adherirse, por supuesto, otros museos y colecciones, privados o de otras administraciones, manteniendo su titularidad. Hay que añadir, además, que las colecciones seguirían, por supuesto, abiertas a efectos de estudio e investigación. Parece de pura lógica y más en tiempos de necesidad, sin embargo la resistencia de los pequeños museos y su personal a perder su estéril independencia e integrarse en una institución mayor y más útil es muy fuerte. No es un caso particular de Barcelona, por supuesto, debe incluso ser mayor en capitales estatales como Madrid, aunque no lo conozco. (4)

Hasta aquí hemos visto fundamentalmente estrategias para el aprovechamiento del patrimonio como recursos económicos locales, sea vinculándolo con procesos productivos y de distribución, sea racionalizando el gasto público de forma tal que, en lugar de mermar sus funciones tradicionales, las optimice. La tercera vía estratégica apunta directamente a la cohesión social y aquí cobra especial relevancia el fenómeno de la verticalidad de las relaciones de las activaciones patrimoniales con la población. Ya hace tiempo (Prats 2005; 2008) que vengo predicando infructuosamente la necesidad de dejar el protagonismo de los procesos de patrimonialización en manos de la población. A pequeña escala, a nivel de una pequeña localidad, por ejemplo, o de un barrio, sin grandes reliquias patrimoniales, no se necesita más que la voluntad del vecindario y el apoyo de un técnico o una técnica en gestión patrimonial para convertir aquello que se decida patrimonializar en un instrumento de encuentro y debate de personas y grupos sociales, de reflexión y construcción de identidades y todo tipo de proyectos colectivos. Evidentemente no toda la población participará por igual ni desempeñará las mismas tareas, incluso puede darse un rechazo por parte de algunos sectores, como en cualquier otra iniciativa. Aquí es donde el papel del gestor o gestora patrimonial cobra especial relevancia, por una parte en el propio hecho de promover la iniciativa y asociar a ella a los agentes locales más activos e interesados, por otra parte en lamayor implicación posible del resto de la población, prestando objetos, contextualizándolos narrativamente, debatiendo colectivamente sobre el sentido de la exposición y finalmente asistiendo y mostrándola como propia. Hay dos puntos especialmente sensibles en esta forma de trabajar el patrimonio: el primero es conseguir hacerlo a coste prácticamente cero, mediantelocales públicos, recursos materiales (ya sean elementos patrimoniales o soportes museográficos) donados o prestados por la población, y, si es posible, con los honorarios $\mathrm{y}$ otros gastos menores cubiertos por administraciones externas. Es importante mostrar 
como se pueden crear activaciones patrimoniales más que dignas a coste prácticamente cero y, sobre todo, firmemente imbricadas en el tejido social y sus aspiraciones. En este sentido es igualmente importante saber sugerir el tema o cuestiones a tratar que, por lo menos en una primera experiencia, conciten el mayor interés y unanimidad posible de forma que la aceptación por parte de la población sea convincente, para lo cual no es menos importante saber contemplar en ella, en la exposición, el mayor número de sensibilidades de forma que no se produzcan fenómenos de exclusión, o se produzcan de una forma insignificante, y menos de estigmatización de colectivos o de personas. Esto ha sido muy difícil de llevar a cabo hasta el presente porque en el ámbito del patrimonio han primado los intereses políticos y económicos por encima de los sociales y culturales, pero, precisamente en esta situación de crisis, cuando los recursos económicos para ese tipo de iniciativas se hallan congelados, cuando la reflexión colectiva es más necesaria que nunca, es cuando este camino, que estoy seguro que puede dar frutos muy interesantes y enseñarnos a utilizar el patrimonio como un instrumento de diálogo y convivencia, -incluso, por qué no, de lucha-, tiene, si se dan las iniciativas que siempre tienen que partir de la voluntad individual o de un pequeño grupo, unas posibilidades de realización que no han existido en otros momentos.

\section{TURISMO Y PATRIMONIO EN UNA COMARCA DE LA CATALUÑA INTERIOR}

Veamos brevemente como se presentan algunos de los problemas mencionados y como se podrían articular estas vías estratégicas de aprovechamiento económico y cohesión social mediante el patrimonio en una comarca, administrativamente formalizada, del interior de Cataluña.

La comarca se halla situada a una hora y media de promedio de la conurbación de Barcelona, cruzada por una vía rápida que, por medio de un túnel, la comunica también con otra comarca, pirenaica, muy frecuentada por visitantes barceloneses tanto en verano, por su agradable clima y paisaje, como en invierno, por la amplia oferta de estaciones de esquí. Por tanto, nuestra comarca puede decirse que, en cierto modo, se convierte en un territorio de paso, especialmente para las clases medias e ilustradas que frecuentan la comarca pirenaica vecina. Sin embargo, se trata de una comarca con importantes y abundantes atractivos patrimoniales, tanto naturales como culturales, pero que no consiguen generar un saldo positivo de riqueza si tenemos en cuentael montante de la inversión de las administraciones públicas y el claramente insuficiente retorno vía ingresos directos e indirectos, por lo cual ya veremos si el modelo, en este contexto, se podrá mantener. La atracción patrimonial más importante de la comarca que genera ingresos directos recibe 30.000 visitantes al año. Para sus gestores esto representa un éxito, pero, en la práctica, la institución es deficitaria. El 60\% de los visitantes es público escolar, esto hace que el precio promedio real que se paga por entrada sea de seis euros por persona, es decir 180.000 euros al año que, para hacer autónomamente viable la 
institución, deberían bastar, por lo menos, para pagar los salarios de las 10 personas que trabajan en ella en distintos regímenes de contratación, más el mantenimiento, que es caro. La autosuficiencia económica queda pues muy lejos. Es decir, estamos hablando de la atracción patrimonial estrella a mucha distancia del resto, no puede subsistir sin substanciales aportaciones de las administraciones públicas que actualmente se hallan en peligro. Desde una falsa percepción de éxito, la institución no se ha preocupado de completar su oferta, especialmente de restauración, ni siquiera de tener un merchandising atractivo y mucho menos de vincularse estrechamente con la producción artesanal y con el sector turístico. No es más que una muestra de lo que sucede en el resto de la comarca, como en tantas otras: funcionamiento particularizado y muy enfocado a las funciones supuestamente clásicas del patrimonio, especialmente a la didáctica, ignorancia del sector turístico y de las posibilidades de cooperación con otros sectores productivos y un discurso vertical, más o menos conseguido, depende, pero vertical, sin otra relación con la población que constituir un lugar al cual llevar de visita a los invitados. Ningún acto comunitario, ningún protagonismo de la población en la formulación y reformulación de los discursos, más allá del entusiasmo familiar de algún guía que narra espontáneamente historias contadas por sus abuelos. Aunque tenga una apariencia dinámica es un fósil patrimonial más, que se limita a espectacularizar in situ una determinada versión de la realidad.

Patrimonio y turismo no se entienden entre ellos, aquí como en otros tantos lugares. Para las empresas turísticas el patrimonio es un recurso más o menos potente como atracción de clientes y para el sector patrimonial el turismo es algo que sucede sin que se planteen actuar propositivamente. Tampoco hay más entendimiento entre patrimonio y población que el hecho de que el patrimonio habla de ellos y ellos muestran su patrimonio como atracción para forasteros. Ni entre población y turismo, por supuesto, donde la planificación conjunta brilla por su ausencia. Y estamos hablando de una comarca de menos de 50.000 habitantes. La comarca, de antigua tradición fabril y minera, no tiene ahora mayor recurso que el turismo y éste, si se asumiera colectivamente la necesidad de reconversión no sólo del sector sino de otras actividades asociadas, principalmente el patrimonio, tendría viabilidad, por lo menos para estancias cortas basadas fundamentalmente en el mercado de la conurbación de Barcelona. Pero esto requeriría, en primer lugar, una oferta turística madura y cualificada. Actualmente cuenta con unas ocho mil plazas, muy desigualmente distribuidas: 54 hoteles con 1.412 plazas en total; 18 campings con 5.318 plazas en total; y 127 casas de turismo rural que ofrecen en conjunto 1.135 plazas. Esto se completa con 123 bares y restaurantes de diversas categorías. Puede parecer suficiente para el sostenimiento de la población basado en el turismo como primer sector económico, pero el problema no está tanto en el conjunto de plazas ofertadas como en su distribución y características. Entre los 54 establecimientos hoteleros predominan los pequeños y de escasa cualificación, no habiendo en toda la 
comarca ni un solo establecimiento de cuatro estrellas o que presente valores añadidos capaces no sólo de atraer sino de retener a un público de poder adquisitivo medio-alto. Los campings que, por su propia naturaleza, son altamente estacionales y escasamente favorecedores del consumo directo o indirecto, representan más de la mitad de la oferta total de alojamiento, siendo significativamente un camping-resort la mayor empresa de la comarca (como es sabido, el sistema de resort es el que menos beneficios genera para la economía local). Por otra parte, la mayoría de las casas rurales son de hecho alojamientos rurales independientes (lo que ahora en Cataluña se denomina masoveries), es decir, apartamentos o casitas turísticas de alquiler, que suelen generar escaso valor añadido. A todo esto habría que añadir un número indeterminado de segundas residencias que, en cualquier caso, en términos generales, se sabe que presentan un bajo índice de ocupación a lo largo del año, y especialmente fuera de los períodos vacacionales de verano y que, desde el principio de los tiempos de crisis, por supuesto, no han aumentado en absoluto. Entre toda esta oferta destacan uno o dos pequeños hoteles con encanto, alguna casa rural especialmente cuidada y con oferta complementaria y unos pocos restaurantes de visita obligada. Los establecimientos turísticos además se agrupan mayoritariamente en la parte norte de la comarca, más montañosa, quedando la zona más meridional, rica en colonias industriales y otros atractivos virtuales, casi totalmente huérfana de infraestructuras y servicios turísticos (lo cual, por otra parte, no implica que deba quedar al margen de una correcta planificación turístico-patrimonial, las distancias son cortas).

Un territorio con vocación turística, además de la oferta de alojamiento y restauración, en este caso como hemos visto bastante inadecuada, necesita disponer de atracciones turísticas suficientemente potentes como para atraer y retener al turismo, si es posible, más allá de los picos estacionales. Nuestra comarca no cuenta con mar ni con estaciones de esquí alpino y mucho menos con cosmopolitas ciudades. Sin embargo, la riqueza de su patrimonio natural y cultural, la belleza de sus paisajes y monumentos, la bondad del clima y su cercanía a la conurbación de Barcelona le otorgan bazas suficientes como para convertirse en un destino turístico viable basado en la tranquilidad del campo y la montaña y el atractivo y diversidad de su patrimonio. Pero, para esto, el patrimonio debe convertirse, turísticamente hablando, en productos $y$, en este caso, no en cualquier tipo de productos.

Actualmente, los recursos patrimoniales se hallan activados de forma dispersa a lo largo $\mathrm{y}$ ancho de toda la comarca y, lo que es peor, dependiendo de administraciones, ayudas y redes igualmente diversas y con distintas lógicas y cabeceras. El máximo esfuerzo que se ha hecho, y muy loable por cierto, ha corrido a cargo de la oficina comarcal de turismo que ha creado un carnet de fidelización en combinación con algunas activaciones patrimoniales y establecimientos turísticos y un pasaporte para visitar lo que denominan "miradores de la comarca" y que también persigue, mediante puntos intercambiables por 
premios, la fidelización de los visitantes. Como he dicho, se trata de una iniciativa loable, pero insuficiente. Una ordenación de los recursos patrimoniales para su explotación turística, explotación local, por supuesto, requiere su articulación en zonas capaces, pos si solas de retener al visitante a lo largo de todo un día (entiéndase que hablo de zonas geográficamente circunscritas, no de rutas temáticas que requieran grandes desplazamientos). La comarca tiene la posibilidad de ofrecer no menos de siete zonas perfectamente localizadas que permiten disponer de atractivos patrimoniales diversos y potentes y oferta suficiente de restauración (que, aunque también debería mejorar, no es lo más urgente). Esto permitiría tanto estancias de duración media con ofertas estructuradas para ocupar satisfactoriamente no menos de una semana, como altos índices de repetición en estancias cortas, máxime teniendo en cuenta que nos hallamos en una zona de montaña media y por tanto de un paisaje natural extraordinariamente cambiante y bello a lo largo de las diversas estaciones. Vivir pues del patrimonio, es decir, del turismo y de otros sectores de servicios y artesanales a él asociados en la comarca que nos ocupa no es pues ninguna entelequia, sino una empresa perfectamente posible. Requiere cooperación absoluta entre todos los agentes implicados de uno y otro sector, algún esfuerzo de reconversión e implementación en el sector turístico y una previsión de mecanismos de mantenimiento para los recursos patrimoniales que actualmente se mantienen gracias a unas aportaciones públicas de distintas administraciones que no están ni mucho menos aseguradas.

Se trata de una empresa de no poca envergadura, pero, en el fondo, de una zona con 50.000 habitantes donde entenderse en aras de su propia subsistencia económica no debería resultar tan difícil más allá de los inevitables individualismos y enfrentamientos localistas y personales. La crisis les propone un reto, que ademáses científicamente interesante desde la perspectiva del estudio de la gestión del patrimonio y del turismo y de sus mutuas relaciones. De cómo sepan resolverlo dependerá su viabilidad futura, o, por lo menos, la autogestión de sus propios recursos.

\section{EPÍLOGO}

En este artículo se ha hablado mucho de economía, no voy a excusarme por ello. En el contexto actual me resulta imposible hablar o escribir sobre cualquier tema sin tener en cuenta la difícil situación por la que estamos atravesando, una situación que va a transformar el mundo, por lo menos el mundo capitalista avanzado tal comolo conocemos, y seguramente no para bien. Más allá de lo estrictamente personal, me preocupa la realidad que están viviendo las clases populares de nuestra sociedad en general, la falta de trabajo, la extremadamente desigual distribución de la riqueza, los desahucios, los recortes y privatizaciones de los servicios esenciales del estado del bienestar y la ausencia de futuro para toda una generación que hemos preparado con tanto mimo y que, como sabemos bien los que nos dedicamos a la enseñanza universitaria, está sobradamente preparada para tomar un relevo que quien sabe cuando llegará, si es que llega. 
Por eso me miro el patrimonio desde su vertiente más utilitarista, como recurso para vivir, recurso no sólo económico, ciertamente (por eso me he referido a la cohesión social, a la creación de identidades), pero también, y sobre todo ahora, principalmente económico. He tratado de explicar cómo vincularlo con el turismo, además de otras actividades económicas, porque el turismo parece ser un sector que, a parte de otras virtualidades específicamente relacionadas con el patrimonio, resiste mejor la crisis que otros, aunque también se resienta. Supongo que, en tiempos de malestar, esa escapada a otra vida más allá de la cotidianidad se hace más necesaria que nunca. Además, la coyuntura ha favorecido los destinos de proximidad, lo cual, teniendo en cuenta el emplazamiento de nuestro país en general, nos favorece.

Es curioso, e interesante, que frente a este golpe de estado de los mercados, como le han llamado acertadamente algunos, nadie, que yo sepa, haya planteada seriamente vender el patrimonio nacional para saldar la famosa deuda y acabar con el déficit. No serviría de nada, por supuesto, porque la centralidad de la deuda y el dogma de la reducción del déficit no son más que artificios para maniatar al sector público y permitir que el capital (los mercados) se apropie, privatice, todos aquellos servicios de los que en un próximo escenario pueda obtener rentabilidad. Hasta que esto no se consume plenamente, dudo mucho que pueda desaparecer la ortodoxia impuesta por el directorio ultraliberal, aunque alguien se ofreciera a enjuagar la deuda en su totalidad.

Pero lo interesante es que no se ha planteado, y no me refiero a edificios públicos, que es de lo que hablan los políticos cuando se refieren a vender patrimonio, sino a las obras de arte, un valor siempre en alza entre los inversionistas. Estos días se ha vendido una obra menor atribuida a Velázquez por 3,5 millones de euros. Actuando con discreción en el mercado del arte, con la venta de las colecciones del Museo del Prado ${ }^{4}$ (4), o la venta selectiva de obras de diversos museos, la deuda nacional se podría saldar por completo.Obras maestras como las que abundan en nuestros museos se han vendido por cantidades que rondan los ochenta o noventa millones de euros $y$, en algunos casos no suficientemente documentados respecto a alguna obra de Leonardo da Vinci o Van Gogh, se habla de hasta más de dos cientos millones de euros. Como he dicho, seguramente sería inútil ni tan siquiera sacar las cuentas, pero, formalmente, se debería admitir que España habría saneado su deuda, con lo cual, obrando con una cierta sensatez presupuestaria, ya deberíamos estar fuera de la supuesta crisis, $y$, sin embargo, no ha surgido ningún debate al respecto, ni siquiera como hipótesis. ¿Es que acaso las obras de arte son más

4. Según la página web del propio museo "La colección está formada por aproximadamente 7.600 pinturas, 1.000 esculturas, 4.800 estampas y 8.200 dibujos, además de un amplio número de objetos de artes decorativas y documentos históricos. En la actualidad, el Museo exhibe en su propia sede algo más de 1.300 obras, mientras que alrededor de 3100 obras ('Prado disperso') se encuentran, como depósito temporal en diversos museos e instituciones oficiales, y el resto se conserva en almacenes." [www. museodelprado.es, consultada el 10.12.2011] 
importantes que la educación o la asistencia sanitaria o el derecho a una vivienda digna? Hay personas que están muriendo, suicidándose en ocasiones, por las repercusiones de los recortes en estos ámbitos. Y entiéndase que ni siquiera estamos hablando de la desaparición de dichas obras de arte sino de su sustitución por copias solventes, que ni siquiera los críticos más experimentados podrían reconocer como tales a simple vista, todos los museos tienen falsificaciones entre sus colecciones y lo saben.

Este hecho demuestra la fuerza de los referentes patrimoniales como metonimias de la externalidad cultural, reliquias de un dios desconocido. Refuerza la certeza de que, más allá de que se pueda identificar patrimonio con herencia o, -por homonimia y simplemente por homonimia-, se pueda llamar patrimonio a todo lo que sea activado como tal, hay un núcleo duro en el ámbito de lo simbólico que otorga al patrimonio en sí un gran poder, como intenté explicar en 1997 o, más recientemente, en 2009. Un patrimonio que podríamos definir así:“Objetos, lugares o manifestaciones culturales o naturales que guardan una relación metonímica (y por tanto percibida como auténtica) con la superación de la condición humana o de los hechos sociales o naturales entendidos por la sociedad de referencia como dentro del margen de la normalidad, ya sea esta superación individual o colectiva, para bien o para mal, ética o estética; o también con los objetos lugares y manifestaciones del pasado, como tiempo fuera del tiempo, en la medida en que la presencia o evocación del pasado en el presente representa también una ruptura o excepción en el orden natural de las cosas (y por tanto es un referente de la externalidad cultural)". Y que, por lo que parece, se muestra inmune a los avatares de la historia. 


\section{REFERENCIAS BIBLIOGRAFICAS}

ALCALDE, Gabriel, BOYA, Jusèp, ROIGÉ, Xavier (eds.) (2010) Museusd'avui. Elsnousmuseus de societat, Girona: Institut Català de Recerca en Patrimoni Cultural.

ANTON, Salvador, GONZALEZ-REVERTÉ, Francesc (coords) (2007) A propósito del turismo. La construcción social del espacio turístico, Barcelona: UOC

BECK, Ulrich (2004) ¿Qué es la globalización?: falacias del globalismo, respuestas a la globalización, Barcelona: Paidós.

BUSTOS, Camila (2011) "Grupos originarios, patrimonio cultural y turismo indígena en el desierto de Atacanama (Chile)". En Turismo y patrimonio, entramados narrativos, La Laguna: PasosEdita, [Edición electrónica], pp. 49-62

COHEN, Erik, (2005) "Principales tendencias en el turismo contemporáneo", Política y Sociedad, vol 42, no 1, pp. 11-24.

ELIAS, Luis Vicente (2006) El turismo del vino. Otra experiencia de ocio, Bilbao: Universidad de Deusto

GARCIA, José Luis (1998) "De la cultura como patrimonio al patrimonio cultural", Política y Sociedad no 27, pp. 9-20

GASCON, Jordi (2009) El turismo en la cooperación internacional, Barcelona: Icaria.

HAINARD, Jacques (2008) "Lexpologia a la seva justa mesura. La museografia al Museud'Etnografia de Neuchâtel", Mnemòsine. Revista Catalana de Museologia no 4, pp. $57-74$

INIESTA, Montserrat (1994) Elsgabinets del món, Lleida: Pagèseditors.

LÓPEZ-PALOMEQUE, Francesc (2008) "Introducció", Atles del turisme a Catalunya. Mapa nacional de l'oferta i elsproductesturístics, Barcelona: Generalitat de Catalunya, pp. 12-19

MAIRESSE, François (2002) Le Musée. Temple Spectaculaire, Lyon : PressesUniversitaires de Lyon.

MANCINELLI, Fabiola (2011) "Sobre los distintos usos del patrimonio: Análisis de dos estudios de caso en Madagascar" en Turismo y patrimonio, entramados narrativos, La Laguna: PasosEdita, [Edición electrónica], pp. 79-92.

PASTOR, María José y GOMEZ, Domingo (2010) Impactos socioculturales en el turismo comunitario. Una visión desde los pueblos implicados (Selva Lacandona, Chiapas, México), Alicante: Editorial Aguaclara. 
PEREIRO, Xerardo (2011) "El turismo como patrimonio cultural imaginario. Reflexiones a partir del caso del turismo Kuna" en Turismo y patrimonio, entramados narrativos, La Laguna, PasosEdita, [Edición electrónica], pp. 13-25.

PRATS, Llorenç (1997) Antropología y patrimonio, Barcelona: Ariel.

PRATS, Llorenç (2005) "Concepto y gestión del patrimonio local.", Cuadernos de Antropología Social de la Universidad de Buenos Aires no 21, pp. 17-35

PRATS, Llorenç (2008) “¿Museuslocals per a què?”, XX Jornades de Museusi Administració local: Repensar elsmuseuslocals, Barcelona: Diputació de Barcelona, pp.

PRATS, Llorenç (2009) "Heritage according to scale", en M. Anico, E. Peralta (eds.) Heritage and Identity. Engagement and Demission in the Contemporary World, London \& NY, Routledge, pp. 76-89.

PRATS, Llorenç (2011) "Viabilidad turística del patrinomio", Pasos. Revista de turismo y patrimonio cultural, vol 9, n 2, pp. 249-264

RAMONET, Ignacio (2011) "La gran regresión", Le Monde Diplomatique en español n 194

ROIGÉ, Xavier, FRIGOLÉ, Joan (eds.) (2010), Constructing cultural and natural Heritage, Girona: InstitutCatalà de Recerca en Patrimoni Cultural

ROBERTSON, Roland (1992) Globalization: Social Theory and Global Culture. London: Sage.

ROBINSON, Andy (2011) “La gran depresión griega”, La Vanguardia, 7.12.2011

SYMARD, Cyril (1992) “Un concept nouveau, l'économuséologie", en RégisNeyret, Le patrimonineatout du developpement, Lyon : PressesUniversitaires de Lyon, pp. 137-143

UNESCO (2008) Resoluciones y decisiones 1946-2007, Paris: UNESCO [edición en CD$\mathrm{ROM}]$ 